\title{
ELEMENTOS DE ETNICIDAD EN REPRESENTANTES POLÍTICOS DEL PUEBLO AIMARA: ESTUDIO DE LA REVALORIZACION DE ELEMENTOS ÉTNICO AIMARA. PASANKERI-LA PAZ- BOLIVIA (2000-2003).
}

\section{Gloria Eugenia Nogales Vera}

Antropóloga, Licenciada de la Universidad Mayor de San Andrés. Dirección: Calle Conchitas \# 775 La Paz (Bolivia). E-mail: glonog27 @latinmail.com . Tlfno. (+591) - 2 - 2492835.

\section{Resumen}

Los habitantes del barrio Pasankeri de la ciudad de la paz (Bolivia) tienen actitudes de revalorización de lo étnico aimara relacionadas con las manifestaciones de los elementos de etnicidad de los representantes del pueblo aimara y la continua práctica de los elementos de etnicidad de ellos/as mismos/as.

\section{Palabras clave}

Bolivia, revalorización, aimara, representantes parlamentarios, etnicidad

\begin{abstract}
The inhabitants of the Pasankeri neighbourhood located in La Paz (Bolivia) have attitudes of revalorization of their aimara ethnicity related to the manifestations of the ethnic elements of the aimara leaders, and also to the continuous practice of their ethnic elements.
\end{abstract}

\section{Key words}

Bolivia, revalorization, aimara, parliament representatives, ethnicity

$E^{\prime}$ interés por el proceso urbano-boliviano de revalorización de la identidad de lo étnico aimara en movimientos sociales que, según Álvaro García Linera (2001), fueron estructuras de acción colectiva capaces de producir metas autónomas de movilización, asociación y representación simbólicas de tipo económico, cultural y político de los años 2000 al 2002 y estuvieron lideradas por Felipe Quispe Huanca y Juan Evo Morales Aima. Ambos actores motivaron a que la población poseedora de elementos de lo étnico aimara atravesara un proceso de enorgullecimiento de sus costumbres e 
idioma, ya que las demandas de satisfacciones básicas solicitadas por estos personajes tenían una trama más profunda que consistía en una forma de motivación hacia la revitalización de tales elementos étnico aimaras.

Los RPAs (representantes del pueblo aimara) son conocidos por manifestar sus posiciones ideológicas indigenistas e indianistas, por su intervención en el sindicalismo campesino, y más aún por manifestar la unidad étnica aimara en el contacto con personas en diferentes barrios, y también a través de los medios de comunicación. En la actualidad (2003) ocupan masivamente un espacio en la cámara de diputados y senadores después de 178 años de vida republicana en una situación de discriminación y exclusión hacia lo indígena por parte de el sector dominante y minoritario denominados los ḱaras (ausentes de posesiones económicas, y/o blancos), y mestizos.

Por otra parte la mayoría de los pobladores del barrio Pasankeri -cuya toponimia aimara pasanqiri o pasanqalla significa maíz tostado o reventado- son aimara migrantes de primera, segunda y tercera generación provenientes del área rural del departamento de La Paz. Son portadores de elementos de etnicidad como el acullico, el apthaphi, el idioma aimara, y el uso de algún atuendo que refleje algún tipo de pertenencia aimara. Ellos/as, al igual que los pueblos quechuas, guaraníes, entre otros de Bolivia, han sido discriminados sin lasitud. Discriminación producida por actitudes etnocéntricas de superioridad-inferioridad, pero también de sobreprotección, admiración, indiferencia, compasión, del otro frente al indígena, del indígena frente al otro, del indígena frente al indígena. Pues es probable que aún sabiendo que el color de la piel, la fisonomía, el apellido, y el español hablado incorrectamente, no son parámetros para afirmar que un grupo de individuos pertenecen a un grupo étnico, o a un grupo con componentes étnicos, estas actitudes etnocéntricas todavía permanecen y han sido cuestionadas por Felipe Quispe y por Evo Morales.

Ahora bien, dado que hoy la presencia política de estos representantes se hace muy evidente en el parlamento, lo que se pretende en este trabajo es ver cómo estos elementos de etnicidad que practican los representantes, en estrecha relación con la identidad aimara en general, pueden incidir en las actitudes y procesos de revaloración de la identidad de los pobladores de pasankeri, en revitalizar su práctica, en darles una dosis de rebeldía.

De esta manera, este trabajo tuvo la intención de llegar a conocer este problema desde una mirada antropológica, para lo cual se planteó la siguiente pregunta: ¿Cuál es el papel de los elementos de etnicidad de los representantes del pueblo aimara en las actitudes de revaloración de la identidad de lo étnico aimara de los pobladores del barrio pasankeri?

Y otras preguntas fueron: ¿Qué elementos de etnicidad aimaras portan los pobladores del barrio pasankeri en el cotidiano vivir?, ¿Cuáles son los elementos de etnicidad de los representantes del pueblo aimara desde el año 2000 al 2002?, ¿Existen actitudes de revaloración de la identidad de lo 
étnico aimara en los pobladores del barrio pasankeri, debido a las manifestaciones de los elementos de etnicidad de los representantes del pueblo aimara?

La dinámica de la identidad no concluye en la total transformación de la identidad de lo étnico a cambio de la adopción de elementos modernos, por el contrario, estos elementos modernos se complementan, y colaboran a la denominada revalorización de elementos étnicos (o actitud o manera de actuar más firme, mas contundente, mas fuerte en la acción de valorar, estimar, apreciar los elementos de etnicidad) por motivación de los representantes aimaras y por los mismos pasankerinos/as.

Es evidente que los pueblos no son estáticos. Los grupos étnicos tienen una dinámica en la que se aprende, se reproduce, se transforma, pero también se revaloriza lo que se ha aprendido en el transcurso de la conformación del sentido de pertenencia o identidad étnica. En la actualidad, lo étnico aimara en el barrio pasankeri no es estrictamente entendido como la conformación de un grupo étnico -como en la época de los señoríos o como en la época colonial- sino más bien lo étnico es entendido como un componente que se posee. $Y$ es posible que, bajo la circunstancia de su reproducción, y bajo la circunstancia de las manifestaciones de lo étnico de Evo y Felipe, se esté dando una situación de reafirmación de la identidad que demanda cierta autonomía a nivel municipal y prefectural. Preludio, quizás, de una posible solución no solamente de la insatisfacción de las necesidades básicas, sino también de las relaciones sociales discriminatorias -por quienes los pasankerinos denominan los de la high, los k'aras, los otros- basadas en las intolerancias étnicas departamentales, etc.

La metodología utilizada en la investigación fue cualitativa-cuantitativa. Primero se identificaron los elementos de etnicidad aimaras de los representantes indígenas tanto en publicaciones periodísticas como en grabaciones de sus declaraciones en eventos específicos entre los años 2000 al 2002, de ellas se seleccionaron los elementos de etnicidad más significativos. A la par durante el año 2002, se exploró el barrio, se observó a las personas y se hizo un sondeo de opinión con respecto a las actuaciones de Evo Morales y Felipe Quispe, previo contacto y permiso de dirigentes sectoriales del barrio. Posteriormente, en junio del 2003, se realizó en pasankeri una encuesta cuantitativa. En octubre del 2003 se realizaron entrevistas para identificar los elementos de etnicidad de los pasankerinos y corroborar la presencia de los mismos, así como para conocer aspectos sobre el gusto, aprobación, valorización y revalorización de elementos de etnicidad aimaras y sus razones, utilizando los discursos de los representantes del pueblo aimara. Finalmente, desde el mes de noviembre de 2003 a febrero del 2004 se realizó el vaciado de datos, descripción de hechos, y análisis de la información.

Los conceptos básicos para esta investigación fueron la "etnicidad y sus elementos" y la "identidad", según Díaz Polanco, Héctor (1991), Sánchez Parga, José (1992) y Minda, Pablo (1996), como 
también de Villoro, Luis (1998), Kooning, Kees y Silva, Patricio (1999). Los tres últimos como autores secundarios.

El concepto fundamental de Díaz Polanco, Héctor (1991: 62-61) es que todo grupo social posee su etnicidad propia compuesta por una serie de elementos:

\begin{abstract}
La etnicidad debe ser considerada como una dimensión de las clases, o, si se quiere, como un nivel de las mismas. De esta manera todo grupo social o clase posee una dimensión étnica propia... en lo fundamental puede decirse que [la etnicidad] ó lo étnico consiste en las muy variables formas en que se articulan y estructuran tales elementos de orden sociocultural. Un complejo particular que involucra, siguiendo formas específicas de relación, ciertas características culturales, sistemas de organización cultural, costumbres, y normas comunes, pautas de conducta, hábitos, visión del mundo, lengua, tradición histórica, etcétera.
\end{abstract}

Para este caso estudiado, los elementos de etnicidad están compuestos por actitudes y prácticas culturales como el idioma aimara, el acullico, el apthaphi, y la vestimenta.

Por otra parte, el concepto de identidad de Sánchez Parga, José y Minda, Pablo (1996: 278) consiste en "el [sentimiento] de pertenencia a un grupo étnico, de clase social, cultura o cualquier otra clase de agrupación". En el marco de esta lógica, los elementos más importantes de la identidad son: el dinamismo, la historicidad, y la multiplicidad cuando se piensa en procesos de constitución de las identidades colectivas.

El dinamismo en particular, no sólo reconoce que las identidades se transforman, sino que fundamentan su proceso en el aprendizaje o adquisición (a través de la transmisión), la reproducción o práctica y el cambio o transformación de los elementos de lo étnico. En este último proceso de transformación se incorporan otros elementos étnicos u otros elementos modernos diferentes, y/o se desplazan elementos de lo étnico que se poseía. Sin embargo se ha visto que no es correcto pensar que los procesos del dinamismo maduran alegremente hacia la transformación de la identidad, sin reconocer la utilidad y la estima que se puede tener a un elemento de lo étnico, pues se estaría suponiendo que los grupos sociales no cuestionan si deben valorar con más o menos fuerzas sus costumbres, o su idioma. La autenticidad de la identidad del pueblo (Villoro, Luis: 1998) que solamente rescataría y combinaría lo mejor de los rasgos propios del pueblo y lo mejor de los rasgos ajenos de otros pueblos, que se aprenden, se trasmiten, se reproducen, se transforman, implica también una vuelta a la apreciación, una revalorización de los rasgos del pueblo ya autentico de por sí.

\title{
Evo y Felipe
}

Como ya se dijo, dentro del desarrollo de la investigación; lo primero que se hizo fue identificar los elementos de etnicidad aimaras de Felipe Quispe Huanca y Juan Evo Morales Aima. Esta identificación se hizo a través de publicaciones periodísticas de prensa, publicaciones periodísticas de Internet, de obras nacionales, de grabaciones en cassettes y en video desde el año 2000 al año 2002. Ellos se manifestaron reproduciendo, o nombrando dos elementos de lo étnico: el idioma aimara y las 
costumbres. Éstas son el acullicar o succionar la hoja de coca, vestir ciertos atuendos reconocibles como aimaras, así como el almorzar de una manera comunitaria compartiendo la comida dispuesta sobre una tela extendida en el suelo, o apthaphi.

\section{Felipe Quispe dijo:}

Por lo menos unos 70 indígenas que estén ahí [en el parlamento] olor coca, olor a pachamama [tierra]. (Orduna, Víctor, 2001)

Ahora estamos vestido con la ropa de ellos [los k'aras], algunos se ponen corbata pero [...] si ves en la cara sigue siendo indio. (Orduna, Víctor, 2001).

Yo soy Felipe Quispe Huanca, el cóndor, el primero, el que ha bajado los pantalones a los q'aras, el que ha levantado a nuestra cultura a nuestra raza aymara quechua [...] en realidad soy igual que ustedes, yo soy de apellido Quispe pero me he atrevido a ser candidato esta vez, si es que llegamos al palacio de gobierno. (Registro Nogales, Gloria, 2002)

En primer lugar, dentro del parlamento vamos a hablar nuestra lengua aymara sin complejo, los honorables que no saben leer o escribir en nuestros idiomas mejor que se busquen intérpretes. (Orduna, Víctor, 2002: 13)

Evo Morales dijo:

Defendemos la hoja de coca, queremos comercializarla, exportarla e industrializarla. Vamos a impulsar el uso industrial de la hoja de coca, no de la droga. (Zimmenmann, Ivone: 2002)

La coca es un eje vertebral de la cultura quechua-aymara, un bien de mucho valor social y económico...En el parlamento yo me recupero al tomar el té de hoja de coca. ... Nosotros no lo usamos como alimento, sino para mascar y como té y medicina. (Sepúlveda, Lucía, 2002 )

Señor ex - presidente de la república, ex - presidente, ex - vicepresidente [Jaime Paz Zamora] para su información no soy quechua soy aymara [...] estamos viendo en este momento. Y que el pueblo sepa es el odio que nos tienen; Jaime Paz Zamora en vez de responderle al periodista está atacando al Felipe Quispe está atacando al Evo Morales, es el colonialismo interno que nos tiene bronca, nos tiene hambre. (Radio FIDES, 2002).

Gonzalo Sanchez dice que nosotros estamos insultando. Ellos no solamente nos tratan de insultarnos sino nos agreden, nos matan, [...]. Textualmente dice [el hermano de Gonzalo Sánchez]: que vamos a hacer apenas tenemos unas cuantas granadas de gas que no sirven para nada, porque el viento se lo lleva todo, si disparas, si disparas al aire no pasa nada [...] estos indios de mierda sólo se asustan cuando se les mete bala, eso dice su hermano del Gonzalo Sánchez de Lozada. (Radio FIDES: 2002)

Veamos pues cómo cada uno de estos elementos se manifiesta en el barrio.

\section{La Vestimenta}

De los atuendos aimaras se tiene referencia que el traje de la chola paceña, analizado en la obra de Canavesi, Lissette (1987), es de época colonial, confección española y motivos aimaras. Después del levantamiento de Tupac Amaru en 1781, el Visitador José Arreche hizo que los indígenas vistiesen con indumentarias de los chulos utilizadas en provincias de Madrid-España, de donde también proviene el nombre de chola. Félix Patzi menciona que, "La chola provinciana [usa] polleras largas, topos y sombreros con copa baja" Patzi (2000: 5). Por otra parte también menciona que las hijas de las cholas provincianas, se han autonombrado birlochas.

En el barrio se ha observado el uso de la chola provinciana y de la birlocha. La observación de las vestimentas (junio 2002 - octubre 2003) de las mujeres es simple; una mujer puede vestir pantalones, calzados, sweater, llevando al hijo en sus espaldas cargado en un manto o aguayo (en idioma 
aimara), o bien otra mujer vestida con pollera, sweater, calzados de chola, manta y una bolsa para acarrear los alimentos al hogar.

Alisson Spedding (1997: 68) dice que las vestimentas de los hombres "tratándose de migrantes en un barrio periférico... él [hombre] se viste a la moda occidental, [pero] es igualmente fácil de distinguirlo". Es decir, al hombre migrante es fácil de distinguirlo como partícipe de una clase social, pero queda la duda si también es fácil de distinguirlo como poseedor de elementos étnico aimaras. Por la vestimenta de los vecinos hombres de Pasankeri podría denominárseles birlochos. Los hombres usan vestimentas no exclusivas sólo de lo étnico aimara: las abarcas o calzados que cubren la planta del pie sostenida por unos lazos de cuero pegados a la suela de la misma son un caso. Se sabe que un hombre es poseedor de otros elementos étnico aimaras cuando hablan sobre su identidad y la discriminación que sienten cuando por los de abajo o los de la high que viven en la zona sur de la Paz, y que son gente con mayores ingresos económicos y casualmente criollos o mestizos.

Para todos los casos (vestimenta, acullico, idioma, apthaphi), después de haber identificado elementos étnico-aimaras en Pasankeri, se pasó a cuestionamientos como es el gusto, la aprobación, la valorización y finalmente la revalorización propia o motivada por los diputados aimaras y las razones de las mismas.

El gusto es un sentimiento de felicidad por contemplación de las vestimentas de los RPA's en el parlamento por parte de los pasankerinos. El gusto refuerza el rebrote de la identidad aimara que en la década de los 80 estaba sancionada a ser denominada subcultura. La contemplación promueve la emoción de saber que la sola presencia de la vestimenta indígena en el parlamento es una forma de ocupar espacios no ocupados previamente, aunque el primer artículo de la constitución política del estado reconozca que Bolivia es un país multicultural y multilingüe: "Me gusta, porque así demostramos lo que somos (entrevista no.-2; 28/10/2003)." "Porque antes no se veía que entraban así de pollera, solo era bien vestidos, entonces ahora ya ha cambiado (entrevista no.-5;: 4/10/2003)."

Se gusta de algo que es aprobado. Este simple acto de aprobación del uso de las vestimentas proviene de la opinión positiva que conduce a sentir orgullo sobre la pertenencia étnica. Los pasankerinos aprueban este acto ya que en la década de los cincuenta del pasado siglo los indígenas tenían prohibido ingresar en la plaza Murillo (donde se ubica el palacio de gobierno y el parlamento). También porque aunque hubo representación de la vestimenta con la ex - diputada Remedios Loza (la razón: 1999), la población en común ingresaba a la cámara de diputados con vergüenza y con el temor a ser insultado. Ahora es posible ingresar al parlamento sin tales comportamientos pues ha llegado el momento de vanagloriarse de la masiva presencia de parlamentarios indígenas que demuestran y no ocultan el origen étnico al que pertenecen, si no más bien representan al lugar departamento / grupo étnico- de donde provienen en ámbitos nacionales como internacionales a pesar su poca contribución en la solución de problemas políticos o socioeconómicos en el 2003. 
Porque nosotros somos igual de esa vestimenta aunque nosotros usamos pantalones, pero ellos también tienen derecho a estar en el parlamento. Es que así como nuestros antepasados usaban vestimentas así. O sea porque así nosotros conocemos como eran nuestros antepasados ¿no?, o sea llegamos ver nuestras vestimentas, nuestros idiomas, o sea todos nos encontramos. (entrevista no.- 8; 6/10/2003).

Así con sus vestimentas. Porque yo he visto que tienen. La mayoría están de corbata en otros países, en Bolivia nomás se ve eso. Desde que ha entrado el Goni [Gonzalo Sánchez], desde Banzer [Hugo Banzer] ya estaba. Al Goni [durante la presidencia de Gonzalo Sánchez] lo han agarrado fuerte, y se han entrado los indígenas ahí" (entrevista no.- $6 ; 4 / 10 / 2003$ )

Como bien se dijo, al aprobar los pasankerinos la vestimenta de los RPAs se sienten orgullosos, ya que se ven reflejados y representados en tales delegados. Este parecido o semejanza en Evo Morales y Felipe Quispe es una situación sin precedentes y por ende importante dentro del análisis sociológico de las minorías étnicas. Pues la identidad manifestada en la costumbre de vestir a lo aimara en Bolivia ya no es un motivo de discriminación sino un motivo de enorgullecimiento inclusive en aimaras que sólo usan accesorios étnicos con iconografía aimara porque las vestimentas aimaras son costosas.

\begin{abstract}
Yo me siento orgullosa que las personas de pollera están en el parlamento, porque las de pollera valen. O sea no hacerles diferencia a las de vestido, porque también las de vestido por una parte se hacen las que son buenas, se hacen las personas de la high, y a las de pollera les rebajan pero a mi me ha gustado que entren de pollera pero también para apoyarse, o sea no discutir en el parlamento" (entrevista no.- 8; 6/10/2003)

Porque antes los que teníamos pollera éramos discriminados aquí ya ahora con pollera ya todo es. Los que tenían vestido no más eran [...] Prohibido era antes con pollera ¿no ve?, era discriminado, ¿no ve?. Pero andan con sus polleras en el parlamento, donde sea he visto, en varios institutos he visto con sus polleras y todo, hasta las profesoras ya hay" (entrevista no.- 9; 7/10/2003)
\end{abstract}

Se da, por tanto, en Pasankeri la valorización o estimación del uso de atuendos aimaras en los diputados. Pero también existe otra actitud de valoración: por acción propia, y no a instancia de los diputados.

La revalorización o sobrestimación del uso de atuendos aimaras motivada por los diputados es menor que la valorización del uso de atuendos aimaras a instancia propia: por los antepasados de sus abuelos. En Pasankeri, al vestir a lo aimara, se está valorando ese elemento de etnicidad que representa el origen de su existencia.

\footnotetext{
Yo siempre desde pequeña he sido así, desde chiquita siempre me ha gustado la pollera. Depende algunos son de vestido pero hablan aimara [...]. No, es que ellos nomás [los parlamentarios], yo desde chiquita he sido así, como he venido del campo, entonces yo siempre he sido así, así siempre de pollera." (entrevista no.- 2; 2/10/2003).

Porque como te puedo decir. A mi no me pasa lo mismo. Porque me gusta ser como han sido mis abuelos, y a la misma vez, me gusta ser así aquí. (entrevista no.- 18; 28/10/2003)
}

Los pasankerinos también dicen que los RPAs han proporcionado un incentivo, han motivado a que los habitantes de la ciudad de La Paz asuman una actitud, reaccionen, tiendan a opinar positivamente con respecto a la reproducción del uso de la vestimenta aimara porque es una forma de respuesta rebelde ante actitudes discriminatorias.

Por otra parte hay pobladores con elementos de lo étnico aimara en la ciudad de la Paz, automotivados o estimulados a estimar con más intensidad los atuendos que usan. Esta forma de autorevalorización se da porque es suficiente el simple hecho de continuar con la costumbre, sin 
necesidad de tomar en cuenta la presencia indígena en el parlamento para ello, aunque sientan que sus madres sean discriminadas, a veces de maneras no dichas, sino expresadas gestualmente.

Si ha cambiado, si algo ya reconocemos, al verlos a ellos ya saben de donde venimos. La vestimenta si, ha influido ahora ya no hay vergüenza de ponerse un poncho o agarrar una whiphala [bandera multicolor] ya no (entrevista no.$22 ; 28 / 10 / 2003)$

$\mathrm{Si}$, nó solamente ahora sino siempre ha habido eso. Pero el que ahora haya gente indígena así o sea, nuestras raíces hayan, así en todas partes hay trabajo duro, pero siempre se lo ha hecho pero con un sentimiento de sentirse mas respetado" (entrevista no.- 23; 28/10/2003).

\section{El Acullico}

La succión del jugo de hojas de coca en la boca que en idioma aimara se denomina acullico tiene antecedentes históricos. La hoja de coca de los arbustos de los cocales, que los hombres en Sudamérica cultivaron, y utilizaron como suplemento alimenticio, tuvo un valor comercial, fue un suplemento sagrado, medicinal, y también fue un medio de socialización. El dato más antiguo es de Mauricio Mamani y William Carter (Carter, William y Mamani, Mauricio 1986: 69) en Tiwanacu 1580 a.n.e al 1172 d.n.e.

En Pasankeri, como en otros barrios de la Paz se acullica. La mayoría de las personas alguna vez probaron la hoja de coca ya que es un legado de los padres transmitido a los hijos. Lo común es succionar el jugo pero no ingerir la hoja, o tomar su infusión, porque suponen que tal hoja aplaca el hambre, alivia dolores de cabeza o de estómago, y proporciona energía a trabajadores de mano de obra (albañiles, picapedreros, etc.). Se presupone también que la coca es un legado de los aimaras de escasos recursos económicos, puesto que no tienen condiciones de vida que satisfagan sus necesidades alimenticias. La demostración de que el acullico boleo o pijcheo es una costumbre reconocida como aimara en Pasankeri (75\%) y el resto de la Paz, ayuda a no presuponer una costumbre y también a identificar lo que se podría revalorar, pues se revalora lo conocido y no lo desconocido.

Sentir placer por un alimento, otorga satisfacción al humano. Ver sentir placer por un alimento en otro ser humano es un tema de la kinesia que para los RPAs es importante. Pues el acullico de los diputados tuvo y tiene la intención de provocar reacciones positivas o negativas en quienes los observan. Los pasankerinos por ejemplo afirman disfrutar del momento en que ven a los RPAs hacer uso del acullico pero no en frente de cámaras filmadoras, sino en recesos, o cuando realmente se necesite energía.

El parlamento es un lugar privilegiado anteriormente ocupado en su mayoría por los k'aras que no usaban acullicar, por eso se piensa que todavía no se debería practicar esa costumbre. El gusto por ver el acullico en el parlamento y por estar siendo respetado por otros poseedores de más elementos de lo moderno, es menor que el propio, porque es un legado de los ancestros transmitido a las generaciones actuales y no importa donde ni cuando acullicar, si se tiene hambre. Incluso a pesar de que se reflexione que si se deja de acullicar la persona podría ser integrada en el grupo ḱara. Sin embargo este deseo de enajenación es menor que la fuerza de la costumbre.

(c) Gloria Eugenia Nogales Vera. Publicado en AIBR. Revista de Antropología Iberoamericana, Ed. Electrónica 
Eso está bien para no dormir, no encontrar el cansancio mental, puede ser limitado no exagerado, hay otros que bolean o pijchean, ese exagerado es pues, como a decir cada hora, cada dos horas, pijchan otros, como es el parlamento momentáneo, un rato, es favorable" (entrevista no.-7; 6/10/2003).

La costumbre si. Porque eso de mascar coca es una costumbre por ejemplo mayoría, los abuelitos todos mascan coca. Por ejemplo dicen hay para tener fuerza, no hace llegar sueño pero no sé, a ese extremo, si he probado, no sé, no siento eso como dicen ellos, no lo siento. (entrevista no.- $15 ; 27 / 10 / 2003$ ).

La demostración del acullico de los diputados es aprobado por los pasankerinos porque es una buena razón para identificarse con ellos, además sería un acto mojigato que los RPA's no reproduzcan (pero con mesura) tal legado no solamente aimara sino también quechua, en un lugar donde emiten opiniones importantes mientras acullican en frente de las cámaras, al lado de personas sin esta costumbre que podrían adoptarla.

\footnotetext{
Como te digo, su costumbre de ellos es así ¿no?. Van a una reunión este, encuentro de dirigentes, debe ser su costumbre siempre mascar coca. Entonces ellos los del Goni esos senadores en realidad están con café y el cigarrillo ¿no? . Ahí adentro a mi parecer no deberían de hacerlo [acullicar] porque están en un parlamento, entonces es que dentro de la reunión no sé. (entrevista no.- 21; 28/10/2003).

O sea ellos andan con esa tradición y con eso mueren. Que esta bien la verdad a veces tal vez opinen mal los mismos parlamentarios. O sea los que están vestidos de corbata, opinan mal, y tal vez quieren botar esa tradición del parlamento" (entrevista no.- 6; 4/10/2003).
}

La motivación hacia la valoración o estimación por acción de los diputados que acullican y comparten la hoja de coca se propicia porque lo hacen en el parlamento, donde susceptible de evitarse por vergüenza, es menor que la auto-motivación por valorar el uso desde el antepasado común y su continua transmisión de generación en generación.

\footnotetext{
Yo creo, o sea mi abuelita pijcheaba, siempre compraba coca en el campo. Esito me ha gustado, a veces, pero no siempre seguido, pero siempre la coca a veces encuentro pijcheo [acullico], yo creo que no me puedo olvidar de $\mathrm{mi}$ coca conociendo toda mi vida (entrevista no.- 2; 2/10/2003).

Porque la gente campesina, no es que ha mascado coca en el parlamento para que vean coca por la tele. O pá [para] que transmitan nomás por la radio, mascar coca es lo natural. Este somos herederos de nuestros antepasados, si entra un parlamentario, puede mascar coca ahora sino afuera salir igual, mastican coca, igual no hay nada de extrañeza. (entrevista no.-14; 8/10/2003).
}

Según las charlas cotidianas de los pasankerinos, ellos/as perciben que los RPAs en frente de cámaras televisoras, incentivan a que los habitantes de la ciudad de la paz valoren el acullico. La presencia de este hecho contribuye a que los jóvenes aimaras empequeñezcan sentimientos de vergüenza y miedo a ser discriminados, y se incremente la estimación del uso, renazca su sentimiento de identidad por práctica de este elemento entendiéndose así que para el año 2003 quienes deciden el devenir económico y social son los modernos, y quienes deciden en devenir de lo étnico son los tradicionales: "Esta bien que pijcheen ahí adentro, todo eso, creo que esta bien recuperar todo lo que se estaba perdiendo ¿no?, porque ya se estaba perdiendo ¿no?(entrevista no.2; 2/10/2003)."

En otras observaciones cotidianas de los pasankerinos, se percibió que los habitantes de la ciudad de la Paz se auto-motivan a valorar el acullico, y por el contrario se dice que los diputados han sido incentivados a acullicar en ese espacio porque las personas en la ciudad de la Paz lo hacen. 


\section{El apthaphi}

Marta Cajías menciona que las comidas comunitarias o apthaphis en idioma aimara tienen su origen con "el Inca Roca [Sexto Rey del Perú] quien habría ordenado que las colaciones se realizaran en forma pública" (Cajías, Martha y Paz, María 1992: 67), en un período en el que existía un flujo de intercambio de elementos de lo étnico inca y lo étnico aimara en una primacía de los primeros sobre los segundos, es por eso que "la ley de la hermandad determinó la costumbre de reunirse en ayllu para el consumo de los alimentos, con el fin de que nadie quede privado de ellos, pues, los que más tenían compartían sus alimentos con los desfavorecidos." ver (Cajías et.al. 1992: 67).

En el barrio Pasankeri se acostumbra realizar apthaphis sobre una tela extendida en el suelo donde se colocan alimentos procesados que cada persona lleva para probar con ayuda de la mano a la boca. El apthaphi moderno consiste en compartir la comida, con la mano, sobre un manto extendido en una mesa, o bien, sosteniendo el plato y los cubiertos en la mano, sentado en un banco de poca altura agachando la cabeza. El uso mayoritario de esta práctica $(75 \%)$ corroboró su presencia, que permitirá analizar la valorización y revalorización de este uso por motivación de los diputados y propio.

Se comparten los alimentos que se poseen con motivo de entablar una amistad, en días festivos y extraordinarios -como días de proselitismo presidencial- y en lugares específicos: Iglesia, Escuela, Mercado. Hay habitantes que gustan y otros que no gustan compartir alimentos por higiene, aunque a veces estén obligados ser parte de un apthaphi, y además porque quieren evadir su origen rural campesino y étnico de tercera generación para no ser segregados por los k'aras.

A los pasankerinos les gusta que los diputados practiquen la costumbre de hacer apthaphis porque es una costumbre de sentido colectivo que los invita a distribuir equitativamente alimentos primordiales para la vida de cualquier ser humano: "Si me gusta. Porque la única forma sería de compartir o charlar dialogar con los campesinos del parlamento. (entrevista no.- 7; 6/10/2003)."

El gusto de saber que los diputados practican el apthaphi conduce a aprobarlo. Esta aprobación es una reacción ante las discriminaciones observadas cuando los k'aras -por ejemplo los expresidentes, quienes al ser invitados por los RPA's demostraron gestos de molestia, asco y disgusto, coherentes con su identidad mestiza y criolla.

Se aprueba lo que se gusta o agrada, no así lo contrario. En el caso del apthaphi ocurre que los pasankerinos aprueban el uso del apthaphi en los RPA's denotándose un aire etnocéntrico, al hallar natural a esta costumbre. Por otra parte el apthaphi de antecedentes seculares, sería un medio para lograr compartir no sólo el alimento sino también las ideas a través de la conversación con los otros no indígenas.

Esta bien que compartan. El Goni [Gonzalo Sánchez] no practica esas cosas, apthaphis ni nada. Claro, tal vez uno, viéndolo al Mallku, tal vez por molestarle [Felipe Quispe] ha hecho eso [a Gonzalo Sánchez]. Yo creo que estaba bien" (entrevista no.- 3; 3/10/2003). 
Porque así los parlamentarios sabrían como se siente cuando se hace el apthaphi. Por ejemplo, ellos van a compartir a otros lugares, por ejemplo en el altiplano van a compartir con los indígenas. Yo pienso que si un poco más lo trabajaran, lo pueden hasta hacer renacer esa tradición" (entrevista no.- 16; 27/10/2003).

Los pasankerinos se auto-motivan a estimar lo que consideran digno de aprobación, como lo es el apthaphi porque es una costumbre milenaria que continúa a pesar del pensamiento de que al asentarse en la ciudad (lugar donde existen otras maneras de comer). Sin embargo algunos migrantes de ascendencia campesina y étnico aimara pretenden olvidar esa costumbre tanto por miedo a la discriminación como por los prejuicios impuestos por la idea de subordinación de la condición indígena.

Ellos [los RPAs] no me han motivado, los que me han motivado ha sido quizás mi misma comunidad, o sea donde yo voy. Desde que yo he venido a vivir [a la pasankeri], he visto que sólo compartían un refresco así esas cosas con las autoridades (entrevista no.- $1 ; 2 / 10 / 2003)$.

Porque en la ciudad de la paz. Hay gentes más gentes, personas decentes, no son personas como nosotros por eso también nos discriminan tanto (entrevista no.- 2; 2/10/2003)

Aunque la motivación hacia la valoración del apthaphi estimulada por los RPA's en el parlamento, es menor, ésta se da. Esta costumbre es relativamente aprobada porque sobrepasa las estrategias por las cuales líderes aimaras transitorios pretenden ejemplificar la discriminación étnica. Pero es tan efímera que inclusive puede ser considerada como un anzuelo proselitista.

Algunas personas lo habrá dicho, pero otras personas también no. Yo digo que lo han hecho aquellos indígenas de aquí, lo han hecho para mostrar lo que somos nosotros por demostrar lo que es nuestra cultura, entonces con otras que han compartido comida [...] han querido demostrar lo que somos nosotros, lo que tenemos. Porque comer con cubiertos, con todo, no es de aquí [...] no se para nosotros para que se levanten nuestro pueblos indígenas, si han visto ellos lo han tomado con mucho valor o aquellos poquitos que lo han hecho y hacen lo que nosotros hemos hecho, y para ellos [los diputados] ha sido como fortalecer el hábito la costumbre que tenemos del apthaphi (entrevista no.- 13; 8/10/2003).

El auto-incentivo de la práctica del apthaphi en los habitantes de la ciudad de la Paz, según las observaciones de los pasankerinos es mayor, porque se pueden compartir alimentos y así mitigar el hambre a quien no tiene comida, y su uso supera las actuaciones transitorias de los parlamentarios indígenas: "Los que somos de pollera, hablamos de aimara seguimos a veces siempre tenemos que llevar en algún lado en algún acontecimiento, en una fiestita se hace en la escuela también siempre llevamos comida (entrevista no.-2; 2/10/2003)."

Otros pasankerinos creen que los RPAs incentivaron o motivaron poco a la población paceña a tomar una actitud de valoración de esta costumbre de hacer comidas comunitarias. Creencias corroboradas cuando Felipe Quispe en un momento proselitista visitó Pasankeri para ser conocido.

\section{El idioma aimara}

Thérese Bouysse menciona que "los aymaras en su lengua se reconocen como los Hombres - Haque -, siendo su lengua simplemente la lengua de los Hombres - Haquearu -" (Bouysee 1987: 17). El idioma aimara es otro elemento de etnicidad presente en el barrio Pasankeri (45.8\%) el bilingüismo necesario generó lo que se podría denominar aimarañol. 
Los pasankerinos disfrutan del momento en que escuchan a los diputados comunicarse en idioma aimara. Tanto porque en ese momento los identificados con Evo -aunque habla poco el idioma aimara- y Felipe valoran, aprecian, estiman al idioma, como también porque este acto le da significado a su identidad, aunque no permita la comprensión del contenido de las ideas a las personas que sólo hablan castellano. Inclusive existe la disposición a valorar otros idiomas: "Si me gusta escuchar a los parlamentarios en aimara, solo que otros idiomas no entiendo (entrevista no.- 5; 4/10/2003)." "Porque hay que aprender, no se, me siento feliz cuando yo escucho hablar en aimara en el parlamanto a algunas personas así hablar en aimara, me gusta, si me gusta. (entrevista no.- 6; 4/10/2003)."

Los pasankerinos aprueban las declaraciones en idioma aimara de los diputados. E incluso los que entienden y promueven el conocimiento del vocabulario en los jóvenes opinan, aunque sea en un tono etnocéntrico, que el aimara y sólo el aimara y no otro idioma debería por lo menos ser conocido por otros que sólo hablan castellano.

\footnotetext{
Yo como he dicho anteriormente, estoy de acuerdo con que todo lo andino se recupere, lo que se está perdiendo. Y también estoy de acuerdo con que se hable aimara. Alguna vez creo que le he escuchado al mallku [Felipe Quispe], y él ha dicho que si, que si se debe recuperar el que hable la gente o sea el que la gente vuelva a tocar sus temas (entrevista no.- 3; 3/10/2003).

Como sea, no se que el aimara que entre ahí. Que el Goni [Gonzalo Sánchez] hable aimara, que entienda aimara. Porque si dice que es boliviano, tienen que hablar en aymara, yo quisiera que hablen todos aymara ahí (entrevista no.- $6 ; 4 / 10 / 2003)$.
}

En el departamento de la Paz, las personas que viven en las ciudades y lugares urbanizados de áreas rurales, hablan primero castellano y luego aimara. Por el contrario en el área rural se habla primero aimara y luego castellano. En Pasankeri las personas que tienen ascendencia rural en primera, segunda o tercera generación, aprueban la práctica auto-motivada del idioma, porque ayuda a superar el temor a ser discriminados por quienes hablan sólo español y también por los bilingües. Es así que los hijos/as retoman las conversaciones en aimara iniciadas por los padres

Es útil conocer este idioma para la comunicación. Esta aprobación se da sin necesidad de que las personas se sientan inspiradas en los diputados para reforzar sus usos. En el siglo XXI se ha permitido hablar en aimara en un espacio solamente ocupado por los modernos identificados con el idioma español y, aunque algunos tradicionales identificados con el idioma aimara, encuentren banal la ocupación en el espacio de los modernos -porque tienen otras formas de representación cuya organización diferenciada se basa en la rotación anual de representantes, en un ambiente socioétnico que los considera personas o aimaras poseedoras de costumbres, idioma, religión, ideología y vida- el hablar en aimara en el parlamento no puede dejar de ser calificado como positivo por quienes viven en Pasankeri.

Hablan porque es su lengua originaria y como se ve al Mallku [Felipe Quispe], el Mallku no quiere perder nada de lo que es realmente así del campo. El incluso en aymara les habla a los diputados [...] no me identifico así bien del todo, pero me gusta escucharles [...] si me gusta escuchar nada mas así (entrevista no.- 3; 3/10/2003)

Aimara, hablamos siempre, siempre hablan siempre es necesario siempre, mascar hasta escribir aimara, leer, algunos no entienden ¿no vé?, algunos no entienden, hablan, si, puede ser bien (entrevista no.- 12; 7/10/2003)

(C) Gloria Eugenia Nogales Vera. Publicado en AIBR. Revista de Antropología Iberoamericana, Ed. Electrónica 
Se gusta y aprueba lo que se valora, y se revalora lo que es digno de revitalizar por el impulso de circunstancias propician tal acto. La actitud de revalorización es un proceso de reflexión del gusto y la aprobación del idioma aimara, por motivación de las manifestaciones explícitas en el parlamento. Y si se daba el caso, ellos/as estaban obligados a relegar sus costumbres, pero ahora han despertado rebeldemente para gritar su identidad étnica. La motivación de revalorización por incentivo de los RPA's aunque reducidos para el año 2003 a manifestar sólo elementos étnicos, y no a imbuirse en temas de otros campos sociales o económicos es importante, pero no supera las expectativas de interés de poder de los pasankerinos.

\begin{abstract}
Si, porque el idioma así aimara era muy ignorado, muy marginado se puede decir. Hasta yo te digo así sinceramente cuando era niño, en el colegio preguntaban quienes sabían hablar aimara, nadie levantaba la mano, ni yo tampoco por temor a que me marginen ¿no? Una vez entrado al parlamento los diputados indígenas, eso está cambiando mucho ya el idioma aimara se lo está empezando a respetar (entrevista no.- 23;28/10/2003).

Nos va demostrar a nosotros que también tenemos que demostrar, nos pueden dar tal vez un ejemplo de seguir delante de no olvidar aquello tan rico de nuestra cultura de no cambiarlo, variarlo, ni de guardarlo sólo para un museo aimara. Esto era así el aimara y nada más. Pero para nosotros tiene que ser algo practico para nosotros [ ... ] pero por mas que hablemos de gobierno hay aimara, debería ser parte más de nosotros, no ha habido ningún cambio (entrevista no.- 13; 8/10/2003).
\end{abstract}

Por otro lado, la auto-revalorización pasankerina se da porque la motivación hacia la revalorización por parte de los diputados es efímera e inclusive titiritesca. Más bien encuentran que el aprendizaje, la reproducción del idioma con sus cambios pertinentes, es más que suficiente inclusive para superar la discriminación

\footnotetext{
La verdad, antes de que entren así los diputados indígenas, yo ya había tomado en cuenta que el idioma aimara no se debía ignorar, eso ya desde colegio me daba cuenta ¿no?, que ese idioma no se debe ignorar si tu eres de una familia de raíces indígenas porque lo voy a ignorar, yo soy de ahí, no yo ya he pensado así antes de que ellos entren al parlamento (entrevista no.- 23; 28/10/2003).

Porque quizás como dije antes no sabemos valorar lo que tenemos, nos alejamos de nuestra cultura y hasta queremos olvidar que somos también aimaras, y no queremos eso. (entrevista no.- 1; 2/10/2003).
}

Lo contrario ocurre cuando los pasankerinos pasan a opinar que los habitantes de La Paz, ellos/as encuentran que la comunicación de los diputados aimaristas en el parlamento es revalorada, porque estos diputados hicieron recordar que cuando uno se expresa en su idioma materno tan útil regionalmente se siente mucho más orgulloso del origen étnico. La autonegación del conocimiento del idioma aimara por quienes migraron de áreas rurales hacia la ciudad de La Paz, a causa de la discriminación, en algunos casos fue superada por la intervención de diputados aimaristas en el parlamento. Las personas segregadas en la ciudad han enaltecido su autoestima aunque las acciones de los diputados sólo se limitan a demostrar elementos de lo étnico, en lugares donde se decide el destino de este estado multicultural, teniendo la oportunidad de apoderarse de las instituciones del estado.

Por ejemplo, si, están haciendo más mejor la gente que conozca el aymara, por ejemplo muchos por ejemplo del campo, vienen aquí a La Paz, y se hacen a los que no saben del aymara, a veces la gente hay ¿no? del campo, son así dicen ¿no?. Pero ahora con lo que ya en el parlamento mismo ya se está hablando esas cosas ahora la gente ¿no?, en cualquier lado te notan ¿no?, hay que hacerlo una costumbre ya (entrevista no.- 15; 27/10/2003)

Por que hay otros que no saben, y asi por ejemplo uno que hable así también va aprendiendo también, en cambio hay otros que hay que se hace. Pero discriminan todavía también a los que hablan así, porque cuando hablan así piensan que eres del campo todo no se, y te empiezan a discriminar, ya no te hacen valer mucho, pero yo creo que esa parte sería bueno que en el parlamento estén entrando gente de aquí de familias" (entrevista no.- 7; 27/10/2003). 
Por otra parte, los Pasankerinos creen que la motivación hacía la revaloración del idioma es gestado por la misma población aimarista que vive en la ciudad de La Paz, mencionan que la gente que ha venido del campo a la ciudad, está despertando con el objetivo de ser respetado en todo sentido, y también en la comunicación en idioma aimara. Porque de un tiempo aquí las movilizaciones para demandar condiciones de vida más humanas, también han puesto de manifiesto la situación de discriminación del idioma aimara. La indiferencia de los modernos que hablan español por ejemplo es una forma de discriminación que podría ser superada en caso de que quienes saben más español se auto-motiven a aprender aimara.

No han dicho directamente, que si, que siga, pero a veces, ellos mismos, la costumbre misma, han dicho que ellos mismos, nosotros, o sea uno mismo esta acostumbrado lo siga practicando, y no falta personas que tal vez les interesa hacer eso, les gusta, o les llama la atención de alguna manera lo practican, ¿no?, dicen así realmente lo practicaremos pero la costumbre misma (entrevista no.- 3 ; 3/10/2003).

\section{Conclusiones}

El estudio de las etnicidades aimaras en Bolivia, como el caso de áreas urbano andinas en este nuevo milenio, está inevitablemente ligado a ciertos acontecimientos, como las movilizaciones de los años 2000 al 2002. Estas movilizaciones dieron pie a construir renovadas formas de autocomprenderse en las poblaciones como seres fortalecidos y seguros de la reproducción de sus identidades étnico aimaras. Este estudio de caso es un ejemplo de cómo los habitantes en Pasankeri de la ciudad de la Paz en el año 2003 están manifestando actitudes de revalorización de sus costumbres e idioma por medio del incentivo propio y de los representantes del pueblo aimara en la cámara de diputados.

Se gusta, aprueba, valora, y luego se asume una actitud de revalidación, de añadidura de una dosis elevada de estima de las costumbres y el idioma. Sin este proceso de revalidación el carácter dinámico de la identidad puede considerarse incompleto. En Pasankeri se actúa u obra de una manera positiva. Las personas sienten que les siguen perteneciendo estos elementos de etnicidad aimaras y los valoran debido a ciertas motivaciones como son la reproducción de elementos de lo étnico de representantes del pueblo aimara en el parlamento, o como la propia y constante reproducción de tales elementos. Se puede ver, por tanto, cómo la construcción de la dinámica de las identidades colectivas, no siempre termina en el proceso de transformación e inclusive desaparición de una cultura, sino también incorpora actitudes de revalorización.

Los habitantes de Pasankeri han realizado su propio análisis sobre la practica de los elementos de etnicidad aimaras -combinando lo mejor de los elementos modernos y tradicionales propios- y entienden que la dinámica de la etnicidad aimara manifestada en la posesión y practica de sus elementos está atravesando un proceso de revalorización. Esto último, producto de la motivación de sus miembros y de sus representantes. Particularmente, los/as habitantes de Pasankeri están mostrando una serie de actitudes de valoración y de revaloración -especialmente del idioma aimara, 
que manifiestan un sentimiento de pertenencia fortalecido que les otorga seguridad en la decisión de continuar con múltiples costumbres e idioma aimaras.

El trabajo de campo permite ver cómo hablar sobre los elementos de etnicidad de "El Evo" y de "El Mallku", genera en los pasankerinos actitudes de revaloración de su identidad. Al ser continuas las practicas culturales de los habitantes del barrio de Pasankeri, estas actitudes de revaloración, se convierten en un insumo importante para reafirmar su vinculo histórico, su origen aimara, y así revalorizar su identidad en el ámbito urbano.

Estas actitudes de valorización y de revalorización se han dado a raíz de ciertos impulsos externos y propios: Las motivaciones externas de los pasankerinos están ligadas a la presencia de actos de aprobación, gusto, observación pasankerina sobre la valorización y la revalorización de elementos de etnicidad manifestados por los diputados aimaras en el parlamento, en otros habitantes de la Paz, y en ellos mismos. Estas actitudes se dan porque existen sentimientos válidos de orgullo e identificación con estos diputados. Se admira su coraje multitudinario para darle un sentido emblemático a estas unidades en la cámara de diputados, al sobreponerse a las segregaciones cuando visten con estos atuendos, hablan aimara, acullican coca o hacen apthaphis. Por otra parte, las motivaciones propias de los pasankerinos están ligadas a la presencia de actos de valorización y revalorización de ellos/as mismos/as hacia los elementos de etnicidad manifestados y reproducidos por ellos/as mismos. Estas actitudes se dan porque emanan sentimientos de apreciación o estimación de estos elementos, porque persiste la fortaleza, y la fuerza del tiempo para seguir reproduciendo estos elementos. Y también porque el discurso del "Evo" y del "Mallku" sería como una fuerza que no es contradictoria con las aspiraciones culturales de los pasankerinos.

Este proceso de revalorización de elementos de lo étnico aimara, fue en el año 2003 un impulso, un medio para alcanzar metas en los campos político-económicos. Ya que el ingreso de los indígenas aimaras en el parlamento y la demostración de sus elementos étnicos, aunque insuficientes para alcanzar amplias transformaciones, dieron pie a que en el 2006 la población elija un presidente boliviano parecido o igual a ellos en su identidad étnica.

La época de liderazgos étnicos que en cierta medida han dado forma a este trabajo por su relevancia y resultados, fue testigo, entre los años 2003 al 2005, de movimientos sociales con liderazgos colectivos donde todos y cada uno de los habitantes de los barrios de la ciudad de la Paz, empoderados de este proceso de revalorización, tuvieron la oportunidad de exigir con más fundamentos metas practicas del cotidiano vivir. Como son la promoción de la combinación de estos elementos étnicos con tecnología de propiedad universal para la comercialización de capital étnico a través del turismo, por ejemplo, o el aprovechamiento de ofertas de organizaciones internacionales para mejorar los satisfactores básicos de cada barrio. Dichos movimientos sociales también permitieron alcanzar metas de carácter politico-ideológico como el proceso de reforma de la constitución política del Estado Boliviano que tiene previsto comenzar en julio del 2006.

(c) Gloria Eugenia Nogales Vera. Publicado en AIBR. Revista de Antropología Iberoamericana, Ed. Electrónica 


\section{Bibliografía}

Bouysse Cassagne, Thérese (1987). La Identidad Aymara, Aproximación Histórica Siglo XVII. Bolivia: HisbolIFEA

Cajías, Martha y Paz B.de Valda, María (1992). De cómo se Alimentaban Nuestros Antepasados antes de la Llegada de los Españoles. Bolivia: Hisbol.

Canavesi de Sahonero, M. Lissette (1987). El traje de la Chola Paceña. Bolivia: Amigos del Libro.

Carter, William y Mamani, Mauricio (1986). Coca en Bolivia. Bolivia: Juventud.

Díaz Polanco, Héctor (1991). Etnia y Nación en América Latina. México: Consejo Nacional para la Cultura y las Artes.

La razón (1999). La entrevista Remedios Losa. La Razón. Bolivia: Octubre 27: A1.

García Linera, Álvaro; Tapia, Luis y Prada, Raúl (2001). Tiempos de Rebelión. Bolivia: Muela del Diablo.

Kooning, Kees y Silva, Patricio (1999). Construcciones étnicas en américa latina: Construyendo la etnicidad, rumbos y dimensiones. Construcciones étnicas y dinámica sociocultural en américa latina. Quito: Abya Yala.

Minda, Pablo (1996). La identidad. Identidades en Construcción. Quito: Abya Yala.

Morales, Evo (2002). Conflicto por la Tierra $[90$ min]. La Paz Bolivia: Radio FIDES.

Orduna, Víctor (2001) Hay que Indianizar a los Qaras, Semanario Pulso. La Paz Bolivia: 13-19 (10):10.

Orduna, Víctor (2002), Cuando Felipe quería ser Evo Morales, Si yo fuera segundo, Semanario Pulso. La Paz Bolivia: 12-18 (07): 13.

Patzi, Félix (2000). Etnofagia Estatal: Modernas Formas de Violencia Simbólica (Análisis de la Reforma Educativa en Bolivia). Bolivia: Instituto de Investigaciones Sociológicas, Universidad Mayor de San Andrés.

Quispe, Felipe (2002). Conflicto por la Tierra $[90$ min]. Bolivia: Radio FIDES.

Sánchez Parga, José (1992). Producción de Identidades Colectivas. Identidad y Sociedad: Quito: Cela-Puce.

Sepúlveda, Lucía (2003). Evo Morales, la hoja de coca una bandera de lucha. En http://www.puntofinal.cl/543/evomorales.htm. Accedido en 2003 
Spedding, Alison (1997). Investigaciones sobre género en Bolivia, un comentario crítico: Más allá del silencio, las fronteras del género en los andes. Bolivia: ILCA y CIASE.

Villoro, Luis (1998). Estado plural, pluralidad de culturas. México: Paidos y UNAM

Zimmermann, Ivonne (2002). Entrevista con Evo morales. En http://bolivia.indymedia.org/es/2002/07/168.shtml. Accedido el 10 de julio del 2002.

\section{Fuentes primarias}

Felipe Quispe en Chuquiaguillo. (14 de abril del 2002). Cinta 0.1. Lado A. Registro: Gloria Eugenia Nogales Vera.

Entrevista no.-1 (2 de octubre del 2003). Cinta 1. Lado A. La Paz (Bolivia).Registro: Gloria Eugenia Nogales Vera.

Entrevista no.-2 (2 de octubre del 2003). Cinta 1. Lado B. La Paz (Bolivia).Registro: Gloria Eugenia Nogales Vera.

Entrevista no.-3 (3 de octubre del 2003. Cinta 2. Lado A. La Paz (Bolivia).Registro: Gloria Eugenia Nogales Vera.

Entrevista no.-5 (4 de octubre del 2003). Cinta 3. Lado A. La Paz (Bolivia).Registro: Gloria Eugenia Nogales Vera

Entrevista no.- 6 (4 de octubre del 2003). Cinta 3, Lado B. La Paz (Bolivia).Registro: Gloria Eugenia Nogales Vera.

Entrevista no.-7 (6 de octubre del 2003). Cinta 4, Lado A. La Paz (Bolivia).Registro: Gloria Eugenia Nogales Vera.

Entrevista no.-8 (6 de octubre del 2003). Cinta 4. Lado B. La Paz (Bolivia).Registro: Gloria Eugenia Nogales Vera.

Entrevista no.-9 (7 de octubre del 2003). Cinta 5. Lado A. La Paz (Bolivia).Registro: Gloria Eugenia Nogales Vera.

Entrevista no.-12 (7 de octubre del 2003) Cinta 6. Lado A. La Paz (Bolivia). Registro: Gloria Eugenia Nogales Vera.

Entrevista no.-13 (8 de octubre del 2003). Cinta 7. Lados A y B. La Paz (Bolivia).Registro: Gloria Eugenia Nogales Vera.

Entrevista no.-14 (8 de octubre del 2003). Cinta 8. Lados A y B. La Paz (Bolivia). Registro: Gloria Eugenia Nogales Vera.

Entrevista no.-15 (27 de octubre del 2003). Cinta 9. Lado A. La Paz (Bolivia).Registro: Gloria Eugenia Nogales Vera.

(c) Gloria Eugenia Nogales Vera. Publicado en AIBR. Revista de Antropología Iberoamericana, Ed. Electrónica

Vol 1. Num. 2. Marzo-Julio 2006. Pp. 231-248 Madrid: Antropólogos Iberoamericanos en Red. ISSN: 1578-9705 
Entrevista no.-16 (27 de octubre del 2003). Cinta 9. Lado A. La Paz (Bolivia).Registro: Gloria Eugenia Nogales Vera.

Entrevista no.-18 (28 de octubre del 2003). Cintas 9 y 10. Lados B y A. La Paz (Bolivia).Registro: Gloria Eugenia Nogales Vera.

Entrevista no.-21 (28 de octubre del 2003). Cinta 10. Lado B. La Paz (Bolivia).Registro: Gloria Eugenia Nogales Vera.

Entrevista no.-22 (28 de octubre del 2003). Cinta 11. Lado A. La Paz (Bolivia).Registro: Gloria Eugenia Nogales Vera.

Entrevista no.-23 (28 de octubre del 2003). Cinta 11, Lados A y B. La Paz (Bolivia).Registro: Gloria Eugenia Nogales Vera. 